\title{
Retratos sociológicos: uma metodologia de investigação para a pesquisa em educação
}

\section{Sociological portraits: a methodology for research in education}

\author{
Paulo Lima Junior ${ }^{1}$ • Luciana Massi ${ }^{2}$
}

\begin{abstract}
Resumo: Recentemente, a tradição sociológica de Bourdieu tem despontado como uma tendência importante na pesquisa em educação em ciências. Neste artigo, apresentamos algumas das críticas de Bernard Lahire à abordagem de Bourdieu. O propósito central de nossa incursão pelas críticas de Lahire é introduzir e argumentar a metodologia dos retratos sociológicos como recurso importante para a pesquisa em educação científica. Após a descrição dessa metodologia, ela é exemplificada com um retrato sociológico aplicado ao estudo da evasão em um curso de licenciatura em química. O retrato de Diogo ilustra, no nível empírico, algumas propriedades básicas atribuídas às disposições individuais (variabilidade, gênese, transferibilidade, dicotomia e contextualidade). A partir desse retrato, ilustrou-se como a ressonância entre as disposições do aluno e da instituição de ensino permite explicar seu sentimento de adesão e pertencimento ao curso. Em seguida, são sublinhadas outras potencialidades dos retratos sociológicos para os propósitos da pesquisa em educação científica.
\end{abstract}

Palavras-chave: Educação em ciências. Sociologia na educação. Bernard Lahire. Ensino de química. Ensino Superior.

Abstract: Recently, Bourdieu's sociological tradition has emerged as an important trend in research in science education. This paper presents some critiques elaborated by Bernard Lahire towards Bourdieu's sociological approach. The main purpose of our incursion into Lahire's critique is to argue and introduce the methodology of sociological portraits as an important resource for research in science education. After describing this methodology, it is illustrated with a portrait of dropout on an undergraduate course in chemistry. Diogo's portrait illustrates, at the empirical level, some basic features of individual dispositions (variability, genesis, transferability, dichotomy and contextuality). From this portrait, it was possible to illustrate how the resonance between students' and institution's dispositions helps explain their sense of membership and belonging to the course. Finally, we highlight some potentialities of sociological portraits to the purposes of sociological research in science education.

Keywords: Science education. Sociology of education. Bernard Lahire. Chemistry teaching. Higher education.

\footnotetext{
${ }^{1}$ Instituto de Física, Universidade de Brasília (UnB), Campus Universitário Darcy Ribeiro, ICC CSS 334/31, CEP 70910-900, Brasília, DF, Brasil. E-mail: <paulolimaj؟@unb.br>

${ }^{2}$ Departamento de Didática, Faculdade de Ciências e Letras, Universidade Estadual Paulista (Unesp), Araraquara, SP, Brasil.
} 


\section{Introdução}

Recentemente, a tradição sociológica de Bourdieu tem despontado como uma tendência importante na pesquisa em educação científica (CLAUSSEN; OSBORNE, 2013). Ao lado de razões propriamente acadêmicas, essa aproximação com Bourdieu tem ocorrido justamente no momento histórico em que a área de Ensino no Brasil está construindo posicionamentos contundentes sobre o impacto das políticas públicas no ensino de Ciências. Assim, está cada vez mais claro para o conjunto dos pesquisadores de nossa área que um bom ensino de Ciências não se faz somente com soluções técnicas prontamente aplicáveis em sala de aula, mas com um entendimento crítico sobre o funcionamento do sistema de ensino e da própria pesquisa em educação em Ciências, que permitam estender nossos horizontes analíticos para além da sala de aula.

Em oposição à percepção ingênua de que o sistema de ensino colabora com a ascensão social da classe popular, Bourdieu e Passeron (2009) argumentam que o sistema educacional contribui fundamentalmente para a reprodução social. Ou seja, com suas práticas de ensino e avaliação, o sistema educacional contribui para que filhos de pais bem-sucedidos na escola sejam mais propensos ao sucesso escolar, enquanto filhos de pais pobres e sem muito estudo sejam mais propensos ao fracasso e à realização de trajetórias escolares mais curtas ${ }^{3}$. No entanto, assim como qualquer teoria viva, a abordagem sociológica de Bourdieu não está parada no tempo. A partir dos prolongamentos críticos lançados por Bernard Lahire (2002, 2005), é possível reconhecer que as ideias de Bourdieu (em particular, sua teoria sobre o habitus) precisam ser reenquadradas se quisermos realizar análises sociológicas à escala individual. Em outras palavras, a teoria de Bourdieu, ao sublinhar a relação entre reprodução cultural e social, não nos ajuda a compreender o que está em jogo na produção das exceções à reprodução. Por exemplo, que razões sociológicas poderiam ser apontadas para compreender o eventual sucesso escolar de crianças de origem popular? Seriam essas crianças simplesmente excepcionais ou estaria o seu sucesso condicionado por outros elementos de sua experiência social que não têm espaço na análise de Bourdieu? (LAHIRE, 1997).

Os prolongamentos críticos lançados por Lahire produzem uma revisão teórico-metodológica profunda que pode ser considerada vital para o emprego escolar da sociologia de Bourdieu, justamente porque permite dar o tratamento sociologicamente adequado à eventual distância entre as experiências individuais no sistema educacional e aquilo que poderíamos esperar de cada aluno em vista da sua origem social. Neste artigo, introduzimos a análise sociológica de Lahire à escala individual. Em particular, nosso propósito central é apresentar uma metodologia consagrada por esse autor, que consiste da produção de retratos sociológicos a partir de entrevistas (LAHIRE, 2004).

\footnotetext{
${ }^{3}$ No caso de cursos de graduação em Física, por exemplo, essa contribuição escolar para a reprodução social pode ser observada a partir da associação entre a origem social dos alunos e a quantidade de menções de excelência acumuladas por eles nas disciplinas de Física básica (LIMA JUNIOR; OSTERMANN; REZENDE, 2013). Esse compromisso entre origem social e sucesso escolar poderia ser levado em consideração na construção de novos currículos para cursos de graduação em Ciências. Outras implicações do conjunto da teoria de Bourdieu para o ensino e para a pesquisa em ensino de Ciências podem ser encontradas em Lima Junior, Pinheiro e Ostermann (2012).
} 
Retratos sociológicos: uma metodologia de investigação ...

A reflexão teórico-metodológica reportada neste artigo tem origem em investigações mais amplas sobre a trajetória de alunos em cursos de Química (MASSI, 2013) e Física (LIMA JUNIOR, 2013). Visando ilustrar o emprego e a produtividade dos retratos sociológicos, apresentamos aqui o caso particular de um aluno da licenciatura em Química para quem, entre outras coisas, a articulação entre experiência social pregressa e as disposições da instituição de ensino (MASSI; VILLANI, 2014) cumpriram um papel importante. Enfim, argumentamos que essa metodologia constitui uma ferramenta poderosa para a pesquisa em ensino de Ciências no sentido em que permite levantar informações detalhadas sobre o impacto da experiência escolar na trajetória de vida de indivíduos singulares.

\section{Uma sociologia à escala individual?}

Embora qualquer teoria sobre grupos sociais sempre pressuponha a existência de pessoas de carne e osso, a individualidade dessas pessoas pode ser considerada um objeto bastante contemporâneo para o tratamento sociológico. A própria proposta de elaborar uma sociologia do indivíduo pode parecer uma "contradição em termos", na medida em que a nossa concepção de "social" estiver (equivocadamente) construída em oposição a qualidades e processos que só podem ser observados quando analisamos os indivíduos enquanto tais. Afinal, o que distinguiria uma análise sociológica de análises sociopsicológicas, psicológicas ou psicanalíticas? Não seria justamente o fato de que a sociologia trata de (grandes) grupos de sujeitos?

Por exemplo, quando um sociólogo fala de relações de classe e relações escolares, estabelecendo suas propriedades, delimitando o conjunto de bens que, possuídos pelos diversos atores sociais, determinam sua posição na estrutura dessas relações (BOURDIEU, 1996), esse sociólogo está falando de um fenômeno ligado a alguns bilhões de indivíduos que nasceram e morreram ao longo da história (ricos e pobres; eruditos e menos educados; chineses, franceses e latino-americanos). Por essa razão, falar em relações de classe significa fazer uma abstração incrível com relação aos bilhões de formas de viver e aprender que poderíamos encontrar se estivéssemos observando atentamente cada indivíduo.

Ao longo da sua história, a sociologia se colocou muito à vontade com abstrações dessa natureza e magnitude. Ela tem tratado de maneira tão extensiva e contundente tais objetos macrossociológicos (ou seja, que dizem respeito a grupos sociais realmente muito numerosos) que pode ser um pouco difícil imaginar uma sociologia sem todas essas abstrações radicais. Porém, embora possam existir objetos historicamente consagrados pela sociologia (tal como ocorre com as relações de classe abordadas extensivamente por Bourdieu), é possível argumentar que a sociologia não se caracteriza tanto por seus objetos "preferidos", mas por uma maneira específica de abordá-los (LAHIRE, 2005).

Assim, o desafio posto por Bernard Lahire foi o de delinear um tratamento propriamente sociológico para a individualidade dos atores sociais, partindo da tradição de pesquisa de Bourdieu. Evidentemente, esse projeto requer criticar e reelaborar algumas ferramentas teóricas e metodológicas fundamentais. É justamente sobre as reelaborações teórico-metodológicas encaminhadas por Bernard Lahire que tratamos neste artigo. 


\section{A gênese social do indivíduo plural}

Ao longo do seu desenvolvimento, a sociologia acostumou seus praticantes não somente a abstrair qualidades individuais no tratamento de grandes coletivos, mas também habituou os sociólogos a observarem os indivíduos dentro de contextos mais ou menos restritos, tais como: a escola, a ciência, a prática religiosa. Com efeito, sem simplificações dessa natureza, não seria possível falar em uma sociologia do campo escolar, do campo científico ou do campo religioso. Por outro lado, é justamente por analisar indivíduos em contextos restritos que algumas análises sociológicas podem reforçar a ideia de que as ações práticas dos sujeitos são sempre produzidas a partir de um princípio gerador coerente, um habitus.

Considere, por exemplo, o caso fictício de Matheus: um cientista experiente e bastante reconhecido em sua área, bolsista produtividade do Conselho Nacional de Desenvolvimento Científico e Tecnológico (CNPq), e defensor austero das posturas mais ortodoxas de seu campo de investigação. Há quinze anos, as ideias de Matheus e seus colaboradores poderiam ser consideradas bastante inovadoras, mas agora já começam a surgir novidades com as quais Matheus tem muita dificuldade de dialogar. Ele prefere insistir na autoridade dos pesquisadores de sua geração (autoridade essa que sempre retorna a ele mesmo). Em matéria de interpretações da teoria e tratamento de dados, Matheus prefere os clássicos. Os temas de sua investigação são os mesmos (já quase gastos pelo tempo) que eram consagrados há quinze anos.

Como é possível perceber, Matheus é bastante coerente em sua prática profissional (no sentido de que suas práticas parecem ser derivadas de um princípio gerador). Além disso, Matheus parece ilustrar bem a caricatura de ortodoxia que se faz do cientista sênior em praticamente qualquer sociologia. Portanto, podemos associar rapidamente a ortodoxia de Matheus (o princípio gerador de suas práticas) à posição social de prestígio que ele mantém frente aos seus pares. Em outras palavras, podemos recuperar aqui o esquema de Bourdieu e afirmar que as ações de Matheus são orientadas por um habitus de classe dominante no microcosmo do seu campo de investigação.

Contudo, essa análise ideal-típica (caricatural) de Matheus foi muito favorecida pela nossa escolha metodológica de termos dado atenção somente às ações de Matheus no campo científico. Se olhássemos suas ações em outros contextos, certamente obteríamos um cenário muito mais rico e diversificado. Poderíamos, por exemplo, descobrir que Matheus foi baixista em uma banda de rock autoral na sua juventude. Poderíamos também saber que, hoje, ele é jogador de tênis amador e avô. Mais ainda, poderíamos descobrir que Matheus mantém disposições bastante heterodoxas em todos esses contextos, questionando: as restrições alimentares impostas a seus netos, a competência técnica atual dos jogadores brasileiros de tênis profissional, tão bem como a qualidade musical da grande indústria cultural.

Em vista desse quadro mais complexo, o que poderíamos afirmar sobre Matheus enquanto indivíduo? Seria ele portador de um sistema de disposições coerente e derivável de sua posição social? Ou seria ele portador de um patrimônio heterogêneo de disposições que resultam da sua experiência social também heterogênea? No conjunto de sua obra, Lahire explora um argumento bastante contundente sobre a heterogeneidade dos patrimônios individuais de disposições. Segundo ele, sociedades diferenciadas (com forte divisão do trabalho e grande diferenciação de funções) tendem a proporcionar experiências sociais variadas aos indivíduos que a constituem. Tal como a macrossociologia de Bourdieu propõe, sociedades diferenciadas 
são compostas de grupos sociais e instituições aos quais podem ser atribuídos certos sistemas de disposições. Contudo, os indivíduos de carne e osso têm, geralmente, algum trânsito entre esses grupos e instituições. Eles não são somente filhos dessa ou daquela classe social, mas vão à escola, à igreja, a centros esportivos e culturais, ao cinema, ao teatro. É também prerrogativa desses indivíduos incorporarem novas disposições a cada nova experiência social duradoura com a qual se deparam, acumulando, ao longo da sua trajetória de vida, um patrimônio de disposições e competências irredutível a qualquer origem social.

Retomando o exemplo anterior, nada impede que um cientista também professe uma religião, pratique um esporte, ou que tenha filhos. Forjada nessa variedade da experiência social típica das sociedades diferenciadas, a individualidade compreenderia justamente esse patrimônio heterogêneo, essa combinação singular das disposições e competências que os indivíduos adquirem neste e naquele contexto ao longo do seu processo de socialização. Quanto mais variadas forem as trajetórias sociais possíveis, quanto maior for o acesso a experiências sociais distintas, tanto mais autênticas serão essas individualidades e tanto mais notáveis serão as variações individuais dos patrimônios de disposições. Com efeito, mais que sociologicamente compreensível, a individualidade (constituída das variações individuais dos patrimônios de disposições e competências) é sociologicamente necessária em formações sociais diferenciadas por resultar da variedade e heterogeneidade da experiência social incorporada.

\section{A questão da transferibilidade}

Ao mesmo tempo em que imputa coerência e unidade aos patrimônios de disposições incorporados pelos atores sociais, a teoria do habitus de Bourdieu pressupõe alta transferibilidade das disposições adquiridas entre contextos distintos. Com efeito, quando Bourdieu (2008) afirma a boa vontade cultural da classe média, ele a afirma para todos os contextos possíveis de ação dos sujeitos dessa classe média. Por outro lado, a evidência empírica (LAHIRE, 2006) demonstra que a disposição para se apropriar da cultura dominante (chamada boa-vontade cultural) varia entre os indivíduos conforme o contexto. Por exemplo, o mesmo indivíduo que mantém hábitos de leitura altamente legítimos pode manter hábitos pouco legítimos em outros contextos de prática.

Importada da tradição piagetiana para a sociologia, a ideia de que a ação humana é orientada por esquemas coerentes (logicamente estruturados, no caso de Piaget; sociologicamente estruturados, no caso de Bourdieu) e transferíveis entre contextos distintos tem sido amplamente questionada pela psicologia cognitiva contemporânea. Atualizando as palavras de Piaget, alguns psicólogos têm passado da generalidade dos esquemas para a ideia de que esquemas são relativamente dependentes das situações em que são adquiridos. Por exemplo, um aluno que tenha aprendido a aplicar o conceito de força em uma lista de problemas de Física pode não ser tão bem-sucedido ao resolver uma lista com problemas distintos que exijam o emprego do mesmo conceito, mas aplicado em situações diferentes. Igualmente, um pesquisador que tenha adquirido uma disposição à ortodoxia no contexto de sua pesquisa, não manifesta, necessariamente, essa mesma disposição em outros contextos e situações da sua vida (na família, por exemplo).

Evidentemente, a transferibilidade (de esquemas e disposições) é um fato tanto em psicologia cognitiva quanto em sociologia, mas o recurso abusivo e acrítico a essa noção pode ser considerado uma deficiência importante da obra de Bourdieu - deficiência essa que precisa 
ser criticada para não ser reproduzida. Partindo do pressuposto de que as disposições são sempre e prontamente transferíveis, o pesquisador pode inverter o processo da investigação, deixando de comparar contextos diferentes e deixando de gerar a evidência necessária para perceber o que somente essa comparação poderia revelar: (1) se a transferência da disposição em questão ocorreu efetivamente entre os dois contextos; (2) o que efetivamente está sendo transferido de um contexto a outro.

\section{Delineando o conceito de disposição}

Uma tendência usual entre analistas de disposições é elevar um punhado de coisas realmente muito diferentes à categoria de "disposição", tornando esse conceito tão geral quanto vazio. Com o propósito de deixar a ideia de disposição mais bem delineada, Lahire (2004) toma o cuidado de distingui-la ou relacioná-la, por exemplo, aos conceitos de competência e apetência. A distinção entre competência e disposição é bastante elementar na medida em que saber fazer e estar disposto a fazer nem sempre se traduzem um no outro. A distinção entre disposições e apetências é, por sua vez, mais produtiva na medida em que permite investigar as relações que os indivíduos estabelecem com suas próprias ações e disposições. Por exemplo, há quem vá à escola diariamente por rotina e obrigação (disposição sem apetência). Porém, quanto mais precocemente as crianças incorporam apetências favoráveis à escolarização, tanto mais provável é que, em sua juventude, elas não se lembrem da origem social dos motores de sua prática e passem a considerar seus gostos características que existem anteriormente ao seu processo educativo, insistindo que estudam porque é inevitável, porque "eu sempre gostei de estudar" ou porque "é mais forte do que eu".

Lahire (2004) distingue, sobretudo, três tipos de disposições: (1) para agir, (2) para crer e (3) para sentir. Assim, as disposições são determinantes não somente das nossas práticas, mas das nossas maneiras de pensar e de falar (que, em última análise, também são práticas) e das nossas formas de sentir e perceber o mundo à nossa volta. Como não há nenhuma distância importante entre crer e estar disposto a crer, a crença pode ser considerada um tipo de disposição. Com efeito, crenças podem operar como motores importantes da ação prática - como, por exemplo, se observa no caso de indivíduos cristãos que adotam práticas ascéticas (como o jejum) em virtude das crenças que incorporaram mediante educação religiosa. Contudo, não poderíamos compreender tão bem fenômenos como a ilusão, a frustração e a culpa se não fizéssemos uma distinção clara entre crenças e disposições para agir.

Com efeito, vivemos em uma sociedade em que, frequentemente, os atores podem incorporar crenças sem terem os meios ou as disposições para realizarem essas crenças. Vários atores podem incorporar a crença de que é bonito ser magro sem estar disposto a manter uma dieta e exercícios regulares, ficando frustrados com sua aparência. Igualmente, um aluno pode reconhecer a legitimidade da escola e da Ciência, acreditar que elas seriam um veículo eficaz para sua ascensão social, sem ter, contudo, as disposições e competências para lograr sucesso na Ciência escolar. Dessa maneira, essas dissonâncias (intraindividuais) das crenças com disposições para agir ou das crenças com as competências podem explicar, em grande parte, alguns sentimentos de frustração, culpa e ilegitimidade reportados pelos indivíduos. 
Retratos sociológicos: uma metodologia de investigação ...

\section{Do autorretrato ao retrato sociológico}

A entrevista biográfica tem sido a ferramenta mais utilizada para subsidiar análises à escala individual. Por isso, o primeiro problema metodológico que precisamos resolver é o de passar do relato de vida do entrevistado para o retrato de sua história de vida. Em uma análise sociológica à escala individual, estamos, geralmente, inferindo as disposições de um sujeito de pesquisa a partir dos fatos que ele mesmo narra sobre sua vida. Até mesmo porque nenhuma narrativa se constrói sem tomar para si um ponto de vista particular, a narrativa autobiográfica do sujeito não poderia deixar de tentar vender, para o entrevistador, uma imagem mais ou menos acabada de si mesma. Na atenção diferenciada que dá aos contextos de prática, na ênfase que emprega neste ou naquele acontecimento, o entrevistado vai alimentando o entrevistador com os elementos que mais bem vendem sua versão de si.

É importante destacar que não se trata aqui de conceber o entrevistado como um vendedor no senso estrito do termo, nem como um sujeito de má-fé que argumenta uma versão falsa da sua própria história, preocupado com o que dela não deve ser sabido. Frequentemente, é de muito boa-fé que o entrevistado entrega seu relato. Contudo, a adoção e defesa de um ponto de vista sobre si mesmo pelo entrevistado é, antes de qualquer coisa, uma condição inescapável à sua produção autobiográfica. Igualmente, deveria ser considerado indispensável ao entrevistador (nem todas as tradições da sociologia concordariam com isso) guardar alguma distância do autorretrato que se comunica na entrevista.

As versões de si mesmo comunicadas pelos sujeitos de pesquisa podem ser altamente esclarecedoras dos princípios organizadores das suas práticas, e quase nunca são completamente fantasiosas ou ilusórias. Frequentemente, esses autorretratos incorporam conclusões importantes que os sujeitos adquiriram genuinamente no convívio e no confronto com outros atores (por exemplo, "minha mãe diz que eu sou muito..."; “meus colegas dizem que eu deveria ser mais..."). Evidentemente, uma afirmação do tipo "eu sou muito hedonista" não pode ser considerada evidência empírica suficiente para configurar qualquer tipo de disposição hedonista, mas pode despertar o entrevistador para fazer outras perguntas que ele não tinha (e nem poderia ter) imaginado fora do curso próprio da entrevista.

Ao lado dos elementos que o entrevistado destaca, existem inúmeras informações importantes que se revelam justamente quando o entrevistador faz perguntas que o entrevistado não poderia antecipar ou não teria escolhido para falar sobre si. É justamente nessas situações que o entrevistador tem a oportunidade de ganhar um excedente de consciência sobre o entrevistado. Segundo Lahire (2004), contrariamente à ideia ingênua ou demagógica de que toda a verdade sai diretamente da boca dos entrevistados, "o sociólogo não faz completamente o seu trabalho a não ser quando analisa também os inúmeros aspectos da vida passada ou presente do entrevistado que não entram no campo de consciência e de interesse deste" (LAHIRE, 2004, p. 314).

Os erros metodológicos que se poderiam cometer aqui são dois: o primeiro ocorre ao nível da entrevista; o segundo, ao nível da análise. Durante a entrevista, é importante que o entrevistador não se deixe levar completamente pelas perguntas que o entrevistado põe a si mesmo, pela seleção que ele opera na descrição de personagens e acontecimentos. É importante tentar fazer-lhe perguntas que ele mesmo não faria, perguntas para as quais ele não tem respostas prontas. Essas são as perguntas que mais provavelmente darão material para saltar, 
na análise de uma mera reprodução do autorretrato que o entrevistado entrega, para um retrato mais genuinamente sociológico, que incorpora em si o que poderíamos chamar de princípio da não-consciência: que os atores sociais nem sempre têm consciência completa das razões que condicionam suas práticas. Em segundo lugar, é preciso, ao longo da análise, não ignorar os traços disposicionais, que podem ser extraídos de partes importantes da entrevista que os próprios entrevistados negligenciam. É justamente por não poder pressupor que o entrevistado está sempre e o tempo todo consciente das razões de suas ações, que o sociólogo deve investir esforços em adquirir algum excedente de visão que lhe permita realizar uma análise para além daquilo que o entrevistado sabe de si.

\section{Estratégias de condução da entrevista}

A metodologia dos retratos sociológicos pode ser empregada de maneiras e com propósitos bastante diferentes. Embora alguns retratos mais longos tenham sido realizados pelo próprio Lahire (2004), as aplicações dessa metodologia para propósitos da educação, geralmente, implicam fazer retratos mais concisos e direcionados (COSTA; LOPES, 2008; MASSI, 2013).

Para João Teixeira Lopes (2012), os retratos sociológicos são tanto uma técnica quanto uma metodologia, ou seja, uma abordagem metodológica que integra um dispositivo técnico baseado em uma teoria da prática alicerçada na gênese plural e contextual das disposições. Ele explorou a proposta de Lahire em duas obras: no projeto intitulado "Os estudantes e as suas trajectórias no ensino superior” (COSTA; LOPES, 2008), são produzidos cento e setenta retratos de alunos do Ensino Superior; no livro "Género e música de dança” (LOPES et al., 2010), são apresentados dez retratos de mulheres clubbers.

O dispositivo dos retratos sociológicos é usado por Lopes (2012) de forma aplicada, ou seja, produzindo respostas a problemas de pesquisa específicos. Considerando essa especificidade, o autor propõe as seguintes fases de elaboração do retrato: (1) elaboração de roteiro de entrevista biográfica adequado aos objetivos da pesquisa, mas, também, questionando o ator sobre seu posicionamento em esferas da vida diversificadas; (2) realização de duas a três sessões de entrevista, de preferência com intervalo de dias ou semanas entre elas, visando promover a reflexividade do ator; (3) transcrição da entrevista; (4) edição das entrevistas de forma que o resultado seja um discurso na primeira pessoa do entrevistado; (5) construção do retrato, articulando recursos teóricos e material empírico, ou seja, inserindo uma vertente interpretativa superficial; (6) produção de um título que destaque o fio condutor interpretativo do relato, um resumo do percurso e um corpo detalhado. O esquema de apresentação do retrato, descrito na última fase de elaboração, permite três formas de leitura: pelo título (ultrarrápida), pelo resumo (rápida), pelo corpo principal (mais demorada) (LOPES, 2012).

Uma primeira questão prática que, geralmente, se impõe ao entrevistador diz respeito ao papel da empatia durante o processo de entrevista. Dependendo da maneira como a entrevista é conduzida, ela pode se tornar um tipo de confissão íntima ou um espaço para manifestar sentimentos viscerais (de tristeza, rancor, mágoa) que o entrevistador não poderia ignorar sem se desumanizar. De fato, a empatia pode funcionar, no curso da entrevista, como um elemento útil para construir uma atmosfera de confiança mínima dentro da qual entrevistado e entrevistador se comunicam. No entanto, a mesma empatia tende a destruir a análise sociológica na medida em que impede que o entrevistador consiga algum excedente de visão sobre o autorretrato que 
lhe é oferecido pelo sujeito de sua pesquisa. Assim, embora existam tradições em sociologia que evoquem a empatia como princípio central para o processo da entrevista (vide, por exemplo, a fenomenologia), embora a empatia tenha sempre algum uso prático durante entrevistas biográficas, ela não cumpre papel central na metodologia de investigação de Bourdieu e Lahire (BOURDIEU, 2007). Além disso, nas vezes em que o entrevistador diria empaticamente ao entrevistado "Eu entendo sua situação...", poderá sempre dizer assertivamente "Acho que não entendi o que quer dizer. Poderia me explicar melhor?”. Com substituições desse tipo, o entrevistador multiplicará suas oportunidades de colher o material empírico que procura para sua pesquisa.

\section{Um exemplo de retrato sociológico aplicado à investigação da relação aluno-instituição}

Discutimos, a seguir, um retrato sociológico produzido no contexto de uma pesquisa mais ampla sobre a relação aluno-instituição. Investigou-se o caso de um Instituto de Química (IQ) com baixas taxas de evasão, pelo qual seus alunos apresentavam forte sentimento de pertencimento e vinculação (MASSI; VILLANI, 2015). Todos os alunos do primeiro, penúltimo e último ano do curso de licenciatura em Química (noturno) foram convidados a participar desta pesquisa por meio de uma entrevista sobre sua trajetória escolar e acadêmica, que durou em média duas horas. Um total de 16 alunos da licenciatura do primeiro ano, sete do quarto ano e quatro do último ano foram entrevistados.

Os temas e subtemas definidos para a entrevista foram: (1) família, no qual os alunos deveriam descrever o nível de escolarização e a situação econômica e social de seus pais, irmãos, tios, primos e avós; (2) vida escolar (Ensino Fundamental e Ensino Médio), no qual os alunos descreveriam a idade com a qual cursaram as diferentes séries, o tipo de estabelecimento escolar, como era sua relação com os professores e colegas, como era o seu rendimento escolar e qual era a participação da sua família na vida escolar; (3) Ensino Superior, nesse item os alunos contariam se fizeram cursinho, com qual idade ingressaram no Ensino Superior, como se deu a escolha do curso de graduação, como a sua família enxergou essa escolha, como é o seu rendimento escolar no Ensino Superior; (4) práticas culturais, ao longo das entrevistas, os alunos também contariam sobre sua relação com línguas estrangeiras, seus hábitos de leitura, se tocam algum instrumento musical, se praticam esportes, se fazem viagens, se frequentam clubes, livrarias, bibliotecas, museus, shows.

Após a realização das entrevistas, foi feita sua transcrição, sendo que cada uma teve, em média, trinta páginas. A partir desse texto, foram produzidos os retratos sociológicos dos alunos do curso de licenciatura, enfocando sua história escolar e acadêmica. Cabe lembrar que o objetivo central deste artigo é apresentar, teórica e empiricamente, a metodologia dos retratos sociológicos. Nesse sentido, trazemos apenas o resumo de um caso $^{4}$, selecionado porque sua

\footnotetext{
${ }^{4} \mathrm{Na}$ pesquisa mais ampla (MASSI, 2013), foram produzidos 27 retratos sociológicos visando investigar a relação aluno-instituição. Esse conjunto permitiu identificar diferentes tipos de trajetórias acadêmicas em função da integração vivenciada pelo aluno ao longo da graduação. Esse resultado dialoga diretamente com as baixas taxas de evasão observadas nesta instituição.
} 
vivência nos permitiu analisar quase todos os aspectos fundamentais das disposições discutidos neste artigo (variabilidade, gênese, transferibilidade, dicotomia, contextualidade).

\section{Gostos e práticas variados e intensa dedicação às atividades escolares, religiosas, musicais e esportivas plenamente vivenciados e coerentes com o curso de licenciatura}

Diogo tem 23 anos no momento da entrevista (dezembro/2009) e cursa o quarto ano de licenciatura em Química, após ter ingressado no curso de bacharelado e pedido transferência no final do primeiro ano. Seu histórico familiar é marcado pelo investimento na ascensão social, pela escola, por parte da sua família paterna e por uma relação de forte admiração de Diogo por seu pai, que sempre o incentivou a estudar e cultivou, nos filhos, o gosto pela música. Sua trajetória escolar é marcada por: um ótimo desempenho, reconhecido, até mesmo, em Olimpíadas de Matemática, e favorecido por grande influência e acompanhamento de seus pais sobre sua escolarização; grande interesse e curiosidade "natural” pelo conhecimento; e envolvimento nas atividades escolares. Além do bom desempenho escolar, Diogo sempre teve gostos variados, aos quais se dedicou com a mesma intensidade com que se dedicou à escola, como: a música, os esportes e o trabalho no comércio de seu pai. Um dos aspectos mais fortes da personalidade de Diogo é sua disposição coletiva revelada por uma forte preocupação humana e com os outros, valorizando essa dimensão em quase todas suas relações. Esse interesse encontrou local de manifestação na Igreja Católica, cujo grande envolvimento o fará almejar o futuro como padre e buscar o Ensino Médio privado em uma instituição católica. Diante desse contexto, seu ingresso no bacharelado em Química representou uma grande decepção com o engessamento do curso e os relacionamentos pessoais, levando-o ao pedido de transferência para a licenciatura. Nela, Diogo encontrou tempo e espaço para se dedicar a atividades extracurriculares que atendessem a sua procura por válvulas de escape e que contemplassem sua disposição coletiva de preocupação com os outros e de dar um retorno à sociedade pela formação recebida - apresentando um discurso totalmente coerente com os propósitos das ações extensionistas. Assim, participou de várias dessas atividades oferecidas na instituição. Atualmente, ele ministra aulas de Química em um colégio privado e pretende seguir atuando como docente, que lhe permitirá investimento nas relações humanas, e conseguir uma colocação na indústria, que lhe trará uma renda mais alta.

Após apresentação deste resumo, passamos a discutir especificamente as disposições de Diogo, explicando como as identificamos a partir do retrato sociológico completo. Na escola, o bom desempenho de Diogo pode ser explicado pelo seu modo escolar-pedagógico de aprendizagem e ascetismo - duas disposições caracterizadas por Lahire (2004). Essas disposições diretamente associadas e valorizadas no ambiente escolar parecem ter sido incitadas pelo contexto familiar de forte investimento em educação como via de ascensão social - seus avós paternos chegaram a mudar de Estado visando uma formação de qualidade. Selecionamos uma fala do entrevistado que exemplifica seu modo escolar-pedagógico de aprendizagem: "pra estudar eu chamava minha mãe pra fazer aquela chamada oral mesmo. Eu estudava, dava o caderno pra ela, ela começava a perguntar coisas. Eu ia respondendo. Quando eu via que en estava seguro para a prova, eu parava. Era assim”. Fica claro que Diogo contava com o auxílio de sua família para reproduzir, em casa, uma prática 
escolar visando a aprendizagem. Ao longo da entrevista, Diogo trouxe outros exemplos que nos permitem interpretar essas práticas como disposições pelo seu caráter recorrente e por serem frutos da duradoura experiência de toda a sua escolarização. Além dessas, observamos uma forte disposição à autonomia e à iniciativa para a aprendizagem, que contribuíram para o bom desempenho escolar de Diogo:

Eu perguntava para o meu pai. Ele me explicava alguma coisa... Curiosidade natural. Assim, fui aprendendo, Ai, já conseguia ler tudo. Só não conseguia escrever. Não sabia regras de gramática, mas ler eu já conseguia ler! [antes de ingressar na escola] [...]. Ia atrás sempre com as próprias pernas. Tanto que, às vezes, o livro que a professora dava en já tinha lido várias vezes. Por ir sozinho mesmo, ninguém me falava 'não, lê isso', eu ia atrás mesmo.

Essas disposições à autonomia e iniciativa foram reforçadas no ambiente escolar por meio de novas experiências que atualizavam essas fortes disposições para o estudo. Por exemplo, quando um professor da sexta série convidou Diogo para participar de uma Olimpíada de Matemática: "Comecei a participar de bastantes provas, de bastante competição e acabava estudando mais por causa disso". Ele participou duas vezes da Olimpíada Brasileira de Matemática e, na segunda vez, ganhou uma premiação:

Como era escola que estava participando, a premiação ia pra escola, acho que foi um computador, alguma coisa assim. Mas foi muito bom! Eu já me acostumei com o vestibular dessa época e era o quê? Sexta série! A gente já fazia umas provinhas chatinhas, mas foi nessa parte que eu já me acostumei com isso.

Por outro lado, percebemos, no retrato, que, em outro contexto, Diogo apresentava um modo prático de aprendizagem, segundo Lahire (2004, p. 40), "por imitação prática, impregnação e identificação". Sem ter instrução formal, Diogo aprendeu a tocar vários instrumentos musicais (“de ouvido"), por influência de seu pai:

Ele [pai] ouvia muita coisa, ai viciamos em música por causa disso [...] em casa, praticamente toda semana ele vinha com uma fita cassete ou um CD novo, a gente ouvia aquele $C D$ até decorar tudo assim... [risos] fosse o CD que fosse! Ai, acabamos gostando de música. Ficamos com o ouvido afiadíssimo. A gente tem muita facilidade de ouvir uma música e saber nota, saber arranjo, saber isso e aquilo.

Fica clara, então, a presença de uma dicotomia disposicional fruto de uma variação sincrônica na experiência social de Diogo. Como é possível perceber, as experiências familiares em torno da execução musical e da preparação para avaliações escolares produziram em Diogo duas disposições para aprender, que não têm nenhum vínculo lógico entre si e que nem sempre se encontram simultaneamente nos mesmos atores. Tais disposições podem ser chamadas modo prático e modo escolar de aprendizagem. Como a própria dicotomia sugere, modos práticos de aprendizagem são justamente aqueles que tendem a ser mais desvalorizados pela escola. Aprendese sem mestres, métodos ou materiais de ensino, sem critérios de avaliação claros. Tipicamente, 
nos modos práticos de aprendizagem, emprega-se menos abstração e mais trabalho manual. Por essas razões, em um esquema macrossociológico coerente que queira explicar a contribuição da escola na reprodução da distinção entre trabalho manual e intelectual, é razoável sustentar que modos práticos de aprendizagem sejam mais frequentes em meios populares, enquanto modos tipicamente escolares sejam mais cultivados nas frações de classe que têm garantido seu acesso e sucesso na escola. Contra esse quadro coerente, salta aos olhos que dois modos de aprender tão distintos (dicotômicos) tenham sido encontrados ao mesmo tempo no repertório do mesmo ator, mas operando em contextos diferentes. Com efeito, não ter transferido seu modo prático de aprendizagem da execução musical para suas tarefas escolares pode ter contado em favor do sucesso escolar de Diogo na medida em que o aprendizado da ciência escolar presume, tradicionalmente, mais abstrações que trabalhos manuais.

Outra disposição forte em Diogo é a coletiva e humanista - também identificada por Lahire (2004) - marcada, sobretudo, por uma preocupação e solidariedade com os outros, sendo essa dimensão valorizada em quase todas suas relações. Na escola, o bom desempenho de Diogo não impediu que ele tenha um bom relacionamento com todos os colegas. Paralelamente, seus professores preferidos foram justamente os mais humanistas. Ao mesmo tempo, a escola representou um espaço de conscientização quanto aos problemas sociais dos colegas: "o pessoal lá sofria muito em relação a drogas mesmo, em relação a pais problemáticos, família problemática... Lá eu vi mais essa parte, assim, da realidade mesmo". Acreditamos que essa disposição de Diogo tenha se desenvolvido bastante a partir do seu envolvimento com a Igreja Católica, na qual ele e seus irmãos faziam "qualquer coisa que pudesse ajudar. A gente faz̧ia evento de tocar pra juntar dinheiro pra igreja, ou juntar dinheiro pra alguma creche da igreja. Fazia barzinho de Jesus. A gente tocava, participava de tudo". Essa relação com a Igreja vai se fortalecer no Ensino Médio, quando a busca por uma formação em escola particular culminará no ingresso em um colégio católico renomado, com bolsa integral. Essa "preocupação social", como ele mesmo se refere, se revela em diversos momentos, seja nas qualidades que ele admira nos professores, nas atividades que ele desenvolve e, até mesmo, na sua relação com o conhecimento, enquanto algo que deve servir para ajudar os outros. Para Diogo, estudar Química é fundamentalmente um meio de ajudar os outros. Ao ser diretamente questionado sobre isso, ele nos responde que "não tem valor nenhum o conhecimento se não tiver esse lado humano mesmo. Para mim, não tem valor nenhum mesmo. Só o valor egoísta, individual". Segundo ele, a Química funciona como uma ferramenta para ele poder ajudar as pessoas:

$$
\begin{aligned}
& \text { Antigamente podia fažer o que? No máximo ser voluntário das coisas, das mi- } \\
& \text { nhas habilidades, música ou alguma coisa assim, nada além disso. Aqui já posso } \\
& \text { atingir de outras maneiras, desenvolvimento de alguma coisa, ou uma aula boa, } \\
& \text { estando com pessoas, na frente de pessoas pra você poder orientá-las, uma parte } \\
& \text { científica já ou amarrando as duas. Você também tem aquela parte de razão e fé, } \\
& \text { conciliar as duas coisas. Você precisa disso. [...] A hora em que a razão acaba, } \\
& \text { começa a fé- ou a parte transcendental de viver. Mas eu consegui ter mais ferra- } \\
& \text { mentas aqui, aplicar mesmo aqui assim. }
\end{aligned}
$$

Fica claro, então, o aspecto recorrente, duradouro e, neste caso, independente do contexto, dessa disposição de Diogo.

Graças à escola particular e um ano de estudos em curso pré-vestibular, Diogo ingressou no bacharelado em Química em 2005, mas, depois de um ano, pediu transferência para 
a licenciatura porque achou a estrutura do curso "péssima". Também influenciado por sua família, Diogo desenvolveu o hábito de se dedicar simultaneamente a várias atividades, como: escola, trabalho, religião, música e esportes. O caráter duradouro desse hábito pode nos levar a considerá-lo como uma disposição, sobretudo, porque Diogo procurou essa pluralidade na universidade, indiretamente buscando a atualização desta disposição. A disposição humanista e coletiva de Diogo associada a sua disposição a se dedicar a diversas atividades simultaneamente parece realmente incoerente com o perfil e exigências do curso de Bacharelado, talvez daí a identificação quase total com o curso de licenciatura. Nela, Diogo encontrou tempo e espaço para se dedicar a atividades extracurriculares que atendessem a sua "procura por válvulas de escape" (como ele denominava as atividades extracurriculares), e que contemplassem sua preocupação com os outros e com um retorno para a sociedade pela formação recebida - apresentando um discurso totalmente coerente com os propósitos das ações de extensão com as quais ele se envolveu.

Ainda que sejam consonantes com as disposições presumidas pela instituição de ensino em questão, o patrimônio de disposições de Diogo (modo prático e modo escolar-pedagógico de aprendizagem, à autonomia e iniciativa, coletiva e humanista, de dedicação simultânea a várias atividades) revela claramente a ausência de um sistema coerente de disposições, de um princípio gerador de práticas tal como a noção de habitus pressupõe. Segundo Lahire (2004), ao organizar uma lista das disposições de um indivíduo, fica claro que cada um "é o produto de uma mistura bastante sutil de disposições variadas" (LAHIRE, 2004, p. 40), e que essas disposições "não mantém nenhum vínculo de necessidade lógica entre si”.

\section{A produtividade dos retratos sociológicos na pesquisa em educação científica}

Como é possível perceber, a metodologia dos retratos sociológicos nos conduz a um novo olhar na medida em que inscreve a experiência científica e educacional de um ator individual no conjunto de sua trajetória social. Com efeito, a experiência de um ator individual no ensino de Ciências estará intimamente ligada a outras experiências de socialização, e, dificilmente, poderia ser compreendida de maneira mais abrangente sem colocarmos o ensino em relação com outras esferas da atividade humana na qual seus atores individuais também são educados (por exemplo, família, escola, trabalho, religião, prática esportiva e outros espaços da vida cultural). É justamente quando situamos o ensino de Ciências nos diversos contextos individuais que conseguimos encontrar respostas para algumas perguntas tipicamente feitas na pesquisa em educação científica: Por que somente alguns alunos têm tanto interesse pelas Ciências a ponto de ingressarem e permanecerem em um curso de graduação nessa área? Qual é a origem da competência científica dos alunos mais capazes? Quais são as contribuições e impactos reais de um curso científico para o conjunto da experiência humana dos alunos?

A partir do retrato apresentado aqui, pudemos perceber quanto a experiência de Diogo no curso de Química é implicada por suas experiências sociais anteriores. Percebemos, por exemplo, que ter adquirido um modo escolar de aprendizagem desde o convívio familiar pode ter favorecido Diogo em toda sua trajetória escolar. Em particular, sua opção pela licenciatura parece ter sido orientada por uma disposição humanista que não poderíamos ter compreendido 
de maneira adequada se não tivéssemos inserido sua vida religiosa no horizonte desta análise. Além disso, percebemos que Diogo atualizou seu patrimônio de disposições ao ingressar na universidade, graças ao clima institucional, que promoveu uma ampliação e um fortalecimento das disposições existentes. Nesse sentido, acreditamos que o encaixe das disposições institucionais e pessoais representou o principal motivo que explica o sentimento de adesão e pertencimento deste aluno em relação à instituição. Essa consonância entre o patrimônio de disposições de Diogo e as disposições presumidas pelo curso de licenciatura em Química parece ter contribuído diretamente para sua permanência no Instituto de Química (MASSI, 2013).

Ainda que a metodologia dos retratos sociológicos possa ser situada ao lado de outras metodologias qualitativas, é importante sublinhar suas características distintivas. A saber, não buscamos, nesses retratos, uma visão holística qualquer do entrevistado. O que fazemos no processo de produção do retrato é, justamente, objetivar a subjetividade, identificando as marcas do social no individual, estabelecendo uma ponte entre os contextos macrossociológico e microssociológico. No retrato de Diogo, essa objetivação da subjetividade se manifesta na realização de reflexões fundamentadas que estão fora do horizonte de consciência do entrevistado (vide, por exemplo, as considerações sobre seu modo escolar-prático de aprendizagem). Com efeito, dessa orientação objetivadora, emerge uma das principais potencialidades dos retratos.

A objetivação da subjetividade, realizada na busca por um excedente de visão sobre a narrativa autobiográfica do entrevistado, geralmente, conduz a resultados de pesquisas consistentes e coerentes. Esses resultados são construídos tendo como norte um problema de investigação, e condensam dados e análise no mesmo documento, ou seja, são produzidos tendo um referencial teórico sociológico como base, sendo seu produto coerente com essa filiação teórica. Poucas metodologias da área de pesquisa em ensino contemplam esses três aspectos. Considerando essas potencialidades, acreditamos que a adoção dos retratos sociológicos seja frutífera para as pesquisas em educação em Ciências que pretendam uma análise sociológica das práticas individuais, inscrevendo a experiência com a educação científica no conjunto da experiência social de cada ator.

Enfim, os argumentos de Lahire (2002, 2005) mostram-se importantes em, pelo menos, dois sentidos. O primeiro deles é o de estabelecer uma relação mais crítica e uma distância desde as análises macrossociológicas, que sempre operam simplificações e abstrações tremendas sobre os indivíduos de carne e osso que constituem os grandes coletivos analisados. Essa distância saudável das grandes estatísticas é muito importante tanto para a análise sociológica quanto para a vida diária de profissionais educadores. Por exemplo, fora do domínio das grandes estatísticas, faz muito sentido falar no sucesso escolar da classe popular. Ainda que a chance de sucesso seja mais rara nesses meios, um educador fixado nas grandes estatísticas pode adotar uma posição sempre muito fatalista com relação a seus alunos de classe popular. Se, em nível macrossociológico, há uma correspondência mais ou menos clara entre classes dominantes e cultura dominante, essa relação não se verifica tão nitidamente na escala individual. O segundo sentido das contribuições de Lahire, já bastante destacado desde o início deste artigo, consiste em estabelecer um modo propriamente sociológico para o tratamento da individualidade.

A noção de disposição traduz essas considerações de Lahire, ao estabelecer uma relação entre o macro e o micro e entre o social e o individual. Nesse contexto, os retratos sociológicos surgem como ferramentas ideais para identificar e analisar as disposições dos indivíduos. Questionando o tradicional método sociológico de investigação dos atores em contextos específicos, 
por meio dos seus retratos, Lahire pretende evidenciar a contradição e oscilação disposicional dos entrevistados. Segundo ele, "o que salta aos olhos é a configuração relativamente heterogênea que cada patrimônio individual de disposições constitui" (LAHIRE, 2004, p. 323). Apresentamos, neste artigo, extratos de um retrato sociológico aplicado a uma questão de pesquisa, como proposto por Lopes (2012) e Lopes et al. (2010). Por meio desse exemplo, foi possível perceber o caminho de construção de uma interpretação disposicionalista do indivíduo, bem como evidenciar as contradições e oscilações das disposições.

A adoção desta metodologia aplicada a uma questão de pesquisa permite condensar dados e análises em um único produto. Além disso, os retratos sociológicos oferecem uma possível resposta ao antigo problema, das ciências humanas, da orientação social da ação individual.

\section{Referências}

BOURDIEU, P. Compreender. In: A miséria do mundo. Petrópolis: Vozes, 2007. p. 693-713.

. Espaço social e espaço simbólico. In: Razões práticas: sobre a teoria da ação. 10. ed. Campinas: Papirus, 1996. p. 13-33.

. Futuro de classe e causalidade do provável. In: NOGUEIRA, M. A.; CATANI, A. (Org.). Escritos de educação. 10. ed. Petrópolis: Vozes, 2008. p. 81-126.

BOURDIEU, P.; PASSERON, J-C. A reprodução: elementos para uma teoria do sistema de ensino. 2. ed. Petrópolis: Vozes, 2009.

CLAUSSEN, S.; OSBORNE, J. Bourdieu's notion of cultural capital and its implications for the science curriculum. Science Education, Hoboken, v. 97, n. 1, p. 58-79, 2013.

COSTA, A. F.; LOPES, J. T. Os estudantes e os seus trajectos no ensino superior: sucesso e insucesso, factores e processos, promoção de boas práticas. Lisboa: Centro de Investigação e Estudos em Sociologia, 2008. Disponível em: <http://etes.cies.iscte.pt/pub. html>. Acesso em: 12 maio 2015.

LAHIRE, B. A cultura dos indivíduos. Porto Alegre: Artmed, 2006.

. Reprodução ou prolongamentos críticos? Educação e Sociedade, v. 23, n. 78, p. 37-55, 2002.

. Patrimônios individuais de disposições: para uma sociologia à escala individual. Sociologia: problemas e práticas, Lisboa, n. 49, p. 11-42, 2005. Disponível em: <http:// sociologiapp.iscte.pt/pdfs/49/517.pdf>. Acesso em: 12 maio 2015.

. Reprodução ou prolongamentos críticos? Educação \& Sociedade, Campinas, v. 23, n. 78, p. 37-55, 2002. Disponível em: <http://www.scielo.br/pdf/es/v23n78/ a04v2378.pdf>. Acesso em: 12 maio 2015. 
LAHIRE, B. Sucesso escolar nos meios populares: as razões do improvável. São Paulo: Editora Ática, 1997.

2004.

Retratos sociológicos: disposições e variações individuais. Porto Alegre: Artmed,

LIMA JUNIOR, P. Evasão do ensino superior de física segundo a tradição

disposicionalista em sociologia da educação. 2013. 258 f. Tese (Doutorado em Ensino de Física) - Instituto de Física, Universidade Federal do Rio Grande do Sul, Porto Alegre, 2013.

LIMA JUNIOR, P.; OSTERMANN, F.; REZENDE, F. Análise dos condicionantes sociais do sucesso acadêmico em cursos de graduação em física à luz da sociologia de Bourdieu. Ensaio: pesquisa em educação em ciências, Belo Horizonte, v. 15, n. 1, p. 113-129, 2013.

LIMA JUNIOR, P.; PINHEIRO, N.; OSTERMANN, F. Bourdieu en la educación científica: consecuencias para la enseñanza y la investigación. Didáctica de las Ciencias Experimentales y Sociales, Valencia, v. 26, p. 145-160, 2012. Disponível em: <https://ojs. uv.es/index.php/dces/article/view/1925/1448>. Acesso em: 12 maio 2015.

LOPES, J. T. (Org.). Registos do actor plural: Bernard Lahire na sociologia portuguesa. Porto: Afrontamento, 2012.

LOPES, J. T. et al. Género e música eletrónica de dança: experiências, percursos e "retratos" de mulheres clubbers. Sociologia: problemas e práticas, Lisboa, n. 62, p. 35-56, 2010.

MASSI, L. Relação aluno-instituição: o caso da licenciatura do Instituto de Química da UNESP/Araraquara. 2013. 167 f. Tese (Doutorado em Ensino de Ciências) - Universidade de São Paulo, São Paulo, 2013.

MASSI, L.; VILLANI, A. Construction of the dispositions of institutional habitus in the academic field. International Research in Education, Las Vegas, v. 2, n. 2, p. 16-32, 2014. Disponível em: <http://dx.doi.org/10.5296/ire.v2i2.5263>. Acesso em: 12 maio 2015.

. Um caso de contratendência: baixa evasão na licenciatura em química explicada pelas disposições e integrações. Educação e Pesquisa, São Paulo, 2015. No prelo.

Artigo recebido em 01/03/14. Aceito em 18/12/14. 